CLINICAL STUDY

\title{
Gene variants of monocyte chemoattractant protein 1 and components of metabolic syndrome in KORA S4, Augsburg
}

\author{
Eva-Maria Sedlmeier ${ }^{1,5}$, Harald Grallert ${ }^{1}$, Cornelia Huth ${ }^{1,2}$, Hannelore Löwel $^{1}$, Christian Herder ${ }^{3}$, \\ Klaus Strassburger ${ }^{4}$, Guido Giani ${ }^{4}$, H-Erich Wichmann ${ }^{1,2}$, Hans Hauner ${ }^{5}$, Thomas Illig ${ }^{1}$ and \\ Wolfgang Rathmann ${ }^{4}$ \\ ${ }^{1}$ Institute of Epidemiology. GSF National Research Centre for Environment and Health, Ingolstädter Landstraße 1, D-85764 Neuherberg, Germany. ${ }^{2}$ IBE, \\ Chair of Epidemiology, University of Munich, Munich, Germany, ${ }^{3}$ German Diabetes Clinic, German Diabetes Centre, Leibniz Institute at Heinrich Heine \\ University, Düsseldorf, Germany, ${ }^{4}$ Institute of Biometrics and Epidemiology, German Diabetes Centre, Leibniz Institute at Heinrich Heine University, \\ Düsseldorf, Germany and ${ }^{5}$ Else Kröner-Fresenius-Centre for Nutritional Medicine, Technical University Munich, Freising/Weihenstephan, Germany
}

(Correspondence should be addressed to T Illig; Email: illig@gsf.de)

\begin{abstract}
Objective: Monocyte chemoattractant protein 1 (MCP-1) has been suggested to be involved in the development of several components of metabolic syndrome (MetS). The present study investigated the association of nine MCP-1 single nucleotide polymorphisms (SNPs) with MetS, type 2 diabetes mellitus and metabolic risk factors.

Subjects and methods: The population-based study sample comprised 1630 subjects aged 55-74 years from KORA S4 (Cooperative Health Research in the Region of Augsburg Survey 4). Genotyping was carried out by matrix-assisted laser desorption ionization-time of flight (MALDI-TOF) analysis of alleledependent primer extension products.

Results: The MCP-1 SNP c.-3813C > T exhibited trends for differences between the genotype groups in triglycerides, 2-h glucose and uric acid $(P=0.0084,0.014,0.027)$. Other trends were observed for c.-928G $>C$ associated with height and fasting glucose $(P=0.0024,0.033)$, for $c .105 T>C$ with height and leukocytes $\left(P=0.0095\right.$, 0.047), for $c .{ }^{*} 65 C>T$ and $c . * 3879 C>T$ with MCP-1 levels (both $P=0.012$ ) and for $c .-2138 \mathrm{~A}>T$ with interleukin-6 levels. After correction for multiple testing, none of the analysed SNPs, except c.-928G $>C$ in men showed a significant association with MetS, T2DM or other analysed parameters. Haplotype $M C P-1 * 1$ and $c .-928 G>C$ in men $(P=0.0002,0.0004)$ were significantly associated with an increase in height.

Conclusions: This is the first study to investigate the associations of MCP-1 SNPs with MetS. We found trends for several components of MetS. These parameters were hyperlipidaemia, fasting and 2-h glucose, and uric acid. A new finding is that $M C P-1 * 1$ haplotype is associated with height. Further investigation in larger populations is needed to clarify the involvement of MCP-1 in MetS.
\end{abstract}

European Journal of Endocrinology 156 377-385

\section{Introduction}

Monocyte chemoattractant protein 1 (MCP-1) is a member of the CC chemokine family (1). The corresponding gene (MCP-1 or CCL2) is mainly expressed by adipocytes, endothelial cells, macrophages and osteocytes (2-4). MCP-1 expression is stimulated among others by tumour necrosis factor $\alpha$ (TNF $\alpha)$, interleukin6 (IL-6) and IL-1ß and is suppressed by IL-10 $(2,5)$. MCP-1 itself influences the expression of IL-6, $ß_{1^{-}}$ integrins and lipoproteinlipase (6-8). MCP-1 actions are mediated by chemokine $(\mathrm{C}-\mathrm{C}$ motif) receptor 2 (CCR2) (6). MCP-1 seems to play an important role in several of the clustering risk factors of metabolic syndrome (MetS) as well as in the pathogenesis of MetS itself (9). MetS and its risk factors are highly heritable $(10,11)$. It is characterized by visceral obesity, atherogenic dyslipidaemia, hyperglycaemia, hypertension, a proinflammatory state and hyperuricaemia $(12,13)$. MCP-1 has typical proinflammatory properties, like promoting the arrest and transmigration of monocytes $(14,15)$. Additionally, MCP-1 is involved in adipocyte metabolism $(2,7)$. The association of high MCP-1 levels with obesity is clear in mice, but uncertain in humans $(7,16-18)$. It was further shown that increased MCP-1 levels are related to insulin resistance and type 2 diabetes mellitus (T2DM; 9, 17). In addition, MCP-1 is involved in foam cell differentiation and progression of atherosclerosis $(19,20)$.

The association of the single nucleotide polymorphism (SNP) $-2578 A>G$ with higher MCP-1 levels has been investigated in several association studies, although the findings remain controversial (18, 20-23). Rovin et al. demonstrated the functionality 
of this SNP by showing upregulation of IL- $1 \beta$-induced MCP-1 gene expression (24). Two association studies for $-2578 A>G$ and T2DM showed controversial results $(18,22)$. There are very few other association studies assessing metabolic parameters or MCP-1 SNPs. Until now, no study has addressed the potential association of MCP-1 SNPs with MetS.

The present study evaluates whether SNPs of the MCP-1 gene are associated with MetS, according to the International Diabetes Federation (IDF) definition, and its related traits, including T2DM. We therefore conducted an association analysis of the whole gene based on an elderly population-based study sample from KORA S4 (Cooperative Health Research in the Region of Augsburg Survey 4), Germany.

\section{Subjects and methods}

\section{Study population}

KORA S4 (formerly known as S2000) is a populationbased study of adults performed in southern Germany, which contains a rather homogeneous population $(25$, 26). This survey was conducted under the same conditions as the previous three surveys within the WHO MONICA Augsburg project (25). In KORA S4, 1653 subjects were included in the 55-74 years age group. The following number of individuals were excluded for different analyses: MetS (23 individuals with type 1 diabetes, autoantibodies to glutamic acid decarboxylase or diabetes onset in the context of pancreatitis), T2DM (same as MetS +168 non-fasting individuals that were not characterized for diabetic status), quantitative parameters (same as T2DM +231 type 2 diabetes patients). An oral glucose tolerance test (OGTT) was performed in 1353 participants due to an exclusion of 131 subjects with known diabetes, and 169 dropouts as a result of non-fasting, technical problems, vomiting during OGTT and missing 2-h glucose (27). Body weight was measured in light clothing to the nearest $0.1 \mathrm{~kg}$ and height was measured to the nearest $0.1 \mathrm{~cm}$. Waist circumference was measured at maximum abdominal girth to the nearest $0.1 \mathrm{~cm}$. Blood pressure (BP) was measured in a sitting position from the right arm thrice, after 15-min rest periods, using an automatic device (OMRON HEM 705-CP). The mean of the second and third measurement was used for analysis.

Blood glucose was assessed using a hexokinase method (Gluco-quant, Roche Diagnostics). High density lipoprotein (HDL) cholesterol was measured using the phosphotungstic acid method (Boehringer Mannheim). Triglycerides were assessed with the Boehringer GPOPAP assay. Serum IL-6 and MCP-1 levels were measured by ELISA, as described elsewhere $(28,29)$. Population stratification for KORA S4 was excluded by two genomic control studies. Steffens et al. compared 210 SNPs in three German populations (including 730 participants of KORA S4) and detected maximal inflation factor $\lambda=1.779$ between KORA and the most distant population (30). From these 210 SNPs, Winkelmann et al. compared 79 between 550 KORA subjects and 367 controls from all over Germany $(\lambda=1.01)(31)$.

\section{Definition of metabolic syndrome}

MetS was defined according to the IDF for Europid persons by the presence of central obesity (waist circumference $>94 \mathrm{~cm}$ in men, $>80 \mathrm{~cm}$ in women) and two out of four additional factors (32). These factors are (i) raised triglyceride levels $(\geq 150 \mathrm{mg} / \mathrm{dl})$ or specific treatment for this lipid abnormality, (ii) reduced HDL cholesterol $(<40 \mathrm{mg} / \mathrm{dl}$ in men, $<50 \mathrm{mg} / \mathrm{dl}$; in women) or treatment for this abnormality, (iii) raised blood pressure (systolic $\mathrm{BP} \geq 130 \mathrm{mmHg}$ or diastolic $\mathrm{BP} \geq 85 \mathrm{mmHg}$ ) or treatment of previously diagnosed hypertension, (iv) raised fasting plasma glucose $(\geq 100 \mathrm{mg} / \mathrm{dl}$ ) or previously diagnosed T2DM.

\section{Genotyping}

For the MCP-1 gene, all available tagging SNPs from HapMap (September 2005), as well as SNPs that already showed associations, were chosen for genotyping. In addition, one SNP was added per exon, intron and $\pm 5 \mathrm{kB}$. In the $3^{\prime}$ region of the gene, two SNPs were additionally genotyped. Genomic DNA of KORA participants was extracted from blood leukocytes using the Puregene DNA Isolation Kit (Gentra Systems, Minneapolis, MN, USA), according to the manufacturer's recommendation. Genotyping for the MCP-1 SNPs c.-3813C > T, c.-2138A > T, c.$928 \mathrm{G}>\mathrm{C}, \mathrm{c.76}+334 \mathrm{C}>\mathrm{T}, \mathrm{c.} .77-109 \mathrm{C}>\mathrm{G}, \mathrm{c.105T}>\mathrm{C}$, c. $194+25 C>T$, c. ${ }^{*} 65 C>T$ and $c . * 3879 C>T$ (Table 1) was carried out by means of matrix-assisted laser desorption ionization time of flight (MALDI-TOF) analysis of allele-dependent primer extension products as described elsewhere (33).

Table 1 Overview of genotyped SNPs, their localization, synonyms and aliases.

\begin{tabular}{|c|c|c|c|}
\hline SNP & Localization & Synonym & Aliases \\
\hline rs1860188 & $5^{\prime}$ UTR & c. $-3813 \mathrm{C}>\mathrm{T}$ & \\
\hline rs1024611 & $5^{\prime}$ UTR & c. $-2581 A>G$ & $\begin{array}{l}-2578 A>G, \\
-2518 A>G\end{array}$ \\
\hline rs1024610 & $5^{\prime}$ UTR & c. $-2138 \mathrm{~A}>\mathrm{T}$ & $-2136 \mathrm{~A} / \mathrm{T}$ \\
\hline rs3760396 & $5^{\prime}$ UTR & c. $-928 G>C$ & $-927 C / G$ \\
\hline rs2857657 & Intron 1 & c. $77-109 C>G$ & $+764 \mathrm{G}>\mathrm{C}$ \\
\hline rs13306748 & Intron 1 & $c .76+334 \mathrm{C}>\mathrm{T}$ & \\
\hline rs4586 & Exon 2 & c. $105 T>C$ & \\
\hline rs3917888 & Intron 2 & c. $194+25 C>T$ & \\
\hline rs13900 & 3'UTR & c. ${ }^{*} 65 \mathrm{C}>\mathrm{T}$ & \\
\hline rs991804 & $3^{\prime}$ UTR & c. ${ }^{*} 3879 \mathrm{C}>\mathrm{T}$ & \\
\hline
\end{tabular}

SNP synonyms were named to reflect the distance in nucleotides from the translational start point in NM_002982.3 of the Reference Sequence database (http://www.ncbi.nlm.nih.gov/entrez/viewer.fcgi? $\mathrm{db}=$ nucleotide\& $\mathrm{val}=56119169$ ); UTR, untranslated region. 


\section{Statistical analysis}

Violation of the Hardy-Weinberg equilibrium (HWE) was tested by Fisher's exact test. Quantitative parameters that were components of the IDF definition of MetS, such as waist circumference, triglycerides, HDL cholesterol, systolic and diastolic BP and type 2 diabetes were analysed. Additional parameters related to risk factors of MetS were investigated and are shown in Table 2. For parameters consisting of several components, individual components were analysed separately. For example, body mass index (BMI) consists of height and weight, which were analysed separately. Quantitative traits that are normally distributed on the original or logarithmic scale were analysed by model-free linear regression. Traits that were not normally distributed were analysed by the Kruskal-Wallis test. For each quantitative trait and SNP, a global $P$ value was calculated based on the hypothesis that there were no differences between the genotype groups. In case of significant differences between genders in the characteristics of the study population and a trend towards differences between the genotype groups, a global $F$-test was performed separately for men and women. For analysis of BP, subjects with medication against hypertension were generally excluded. Associations of genotypes with IDF-defined MetS or T2DM were assessed by logistic regression. A Bonferroni correction was used to adjust significance level. The number of SNPs, for which correction was needed, was calculated using SNP Spectral Decomposition (34). $P$ values $<0.0004$ were considered to be significant as a result of the correction for 25 traits and 5 effective SNPs, and $P$ values $<0.05$ were considered as a trend for an association. In case of a trend in two SNPs for the same quantitative parameter, haplotype analysis was carried out with R (V. 2.3.1. including haplo.stats package) using the haplo.glm procedure. This procedure performs an iterative two-step expectation maximation, with the posterior probabilities of pairs of haplotypes per subject used as weights to update the regression coefficients, and the regression coefficients used to update posterior probabilities (35). SNPs were selected for haplotype analysis when $D^{\prime}>0.95$ and $r^{2}<0.80$. Linkage disequilibrium (LD) calculation was performed with JLIN (http://www.genepi.com.au/ projects/jlin). An $r^{2}$ value $>0.8$ between two SNPs was considered to be a strong LD. All other analyses were carried out using SAS (V. 9.1, Cary, NC, USA).

\section{Results}

\section{Characteristics of the study population}

Characteristics of the study population are presented separately for men and women in Table 3. Height, weight, waist-to-hip ratio, waist circumference, triglycerides, serum uric acid, systolic and diastolic BP, fasting plasma glucose, leucocyte count and IL-6 levels were significantly higher in men than in women. In contrast, women had significantly higher values for body fat, hip circumference, $\mathrm{HDL}$ cholesterol, $\mathrm{HbA}_{1 \mathrm{c}}$ and adiponectin levels. After log-transformation triglycerides, adiponectin, MCP-1 and fasting insulin levels were approximately normally distributed. HOMA-IR and IL-6 levels were not normally distributed.

\section{Genetic analyses}

Two SNPs, c. $76+334 C>T$ and $c .194+25 C>T$, were monomorphic in the KORA $S 4$ population and thus were not considered further in the manuscript. The genotyping success rates of the seven analysed SNPs ranged from 95.2 to $98.9 \%$. The discordance rate was $<1 \%$. All seven SNPs were in HWE (Table 4). SNPs $c$. ${ }^{*} 3879 C>$ T and $c$. ${ }^{*} 65 C>T$ showed strong LD $\left(r^{2}=0.996\right)$ and, additionally, both showed complete correlation $\left(r^{2}=1\right)$ with $c .-2581 A>G$. A strong LD was also observed between $c .-2138 A>T$ and c. $77-109 C>G\left(r^{2}=0.981\right)$. In six of the seven MCP-1 SNPs, trends towards differences in some of the analysed parameters between the genotype groups were observed using the global F-test. After correction for multiple testing, none of the analysed SNPs showed a significant association with MetS, T2DM or other analysed parameters. However, c.-928G $>$ C in men and haplotype analysis showed a significant association with height (Tables 2 and 5).

\section{Metabolic syndrome and parameters from IDF definition}

None of the analysed MCP-1 SNPs were significantly associated with the presence of IDF-defined MetS (Table 2). No association was found between the seven MCP-1 SNPs and T2DM, even after excluding 200 subjects that were taking lipid-lowering drugs (data not shown). However, c.-3813C $>$ T and c.-928G $>C$ showed trends, for differences in triglyceride levels and fasting glucose respectively, between the genotype groups $(P=0.0084$, 0.033; Table 2).

\section{Parameters related to risk factors of metabolic syndrome}

Within anthropometric parameters, height, analysed as a component of BMI, showed trends towards differences between the genotype groups in $c .105 T>C$ and c. $-928 G>C(P=0.0095,0.0024$; Table 2). In men, a significant association of $c .-928 G>C$ with height was observed $(P=0.0004)$. In the following haplotype analysis, a significant association was observed, as carriers of $M C P-1 * 1$ were $1.3 \mathrm{~cm}$ taller than carriers of the control haplotype $(P=0.0002)$. Haplotype $M C P$ $1^{*} 4$ also showed a trend for $1 \mathrm{~cm}$ taller carriers (Table 5). No trends were observed for parameters related to hyperlipidaemia. For c.-3813C $>\mathrm{T}, 2-\mathrm{h}$ glucose, a parameter related to hyperglycaemia, was 
Table 2 Global $P$ values for all single nucleotide polymorphisms and parameters from nominal analysis.

\begin{tabular}{|c|c|c|c|c|c|c|c|c|c|c|c|c|c|c|c|}
\hline \multirow[b]{2}{*}{ MCP-1 } & \multirow[b]{2}{*}{ Parameter } & \multicolumn{2}{|c|}{$c .-3813 C>T$} & \multicolumn{2}{|c|}{$c .2138 A>T$} & \multicolumn{2}{|c|}{$c .-928 G>C$} & \multicolumn{2}{|c|}{$c .77-109 C>G$} & \multicolumn{2}{|c|}{$c .105 T>C$} & \multicolumn{2}{|c|}{ c. ${ }^{*} 65 C>T$} & \multicolumn{2}{|c|}{ c. ${ }^{*} 3879 C>T$} \\
\hline & & $n$ & $P$ & $n$ & $P$ & $n$ & $P$ & $n$ & $P$ & $n$ & $P$ & $n$ & $P$ & $n$ & $P$ \\
\hline Metabolic & & c:665/ & & c:683/ & & c:682/ & & c:683/ & & c:667/ & & c:677/ & & c:687/ & \\
\hline syndrome $^{\dagger}$ & & $\mathrm{m}: 841$ & 0.12 & $\mathrm{~m}: 874$ & 0.59 & $\mathrm{~m}: 872$ & 0.97 & $\mathrm{~m}: 872$ & 0.46 & $\mathrm{~m}: 833$ & 0.44 & $\mathrm{~m}: 866$ & 0.71 & $\mathrm{~m}: 873$ & 0.64 \\
\hline Parameter from & Waist circumference & 1167 & 0.59 & 1211 & 0.79 & 1210 & 0.97 & 1209 & 0.76 & 1166 & 0.35 & 1198 & 0.70 & 1214 & 0.75 \\
\hline \multirow{7}{*}{ IDF definition } & Triglycerides $^{\mathrm{a}}$ & 1153 & 0.0084 & 1196 & 0.41 & 1195 & 0.34 & 1194 & 0.43 & 1151 & 0.052 & 1183 & 0.34 & 1199 & 0.41 \\
\hline & HDL cholesterol ${ }^{a}$ & 1163 & 0.44 & 1206 & 0.20 & 1205 & 0.79 & 1204 & 0.19 & 1161 & 0.069 & 1193 & 0.59 & 1209 & 0.71 \\
\hline & Sys. blood pressure ${ }^{a}$ & 770 & 0.27 & 791 & 0.34 & 790 & 0.20 & 790 & 0.34 & 764 & 0.80 & 782 & 0.079 & 794 & 0.068 \\
\hline & Dia. blood pressure ${ }^{a}$ & 770 & 0.27 & 791 & 0.70 & 790 & 0.64 & 790 & 0.62 & 764 & 0.29 & 782 & 0.11 & 794 & 0.10 \\
\hline & ${\mathrm{T} 2 \mathrm{DM}^{\dagger}}^{\dagger}$ & c:1163/ & & c:1207/ & & c:1206/ & & c:1205/ & & c:1163/ & & c:1194/ & & c:1210/ & \\
\hline & & $\mathrm{d}: 222$ & 0.23 & $\mathrm{~d}: 227$ & 0.46 & $\mathrm{~d}: 225$ & 0.089 & $\mathrm{~d}: 227$ & 0.46 & $\mathrm{~d}: 214$ & 0.83 & $\mathrm{~d}: 226$ & 0.93 & $\mathrm{~d}: 227$ & 0.67 \\
\hline & Fasting glucose $\mathrm{a}^{\mathrm{a}}$ & 1165 & 0.088 & 1208 & 0.27 & 1207 & 0.033 & 1206 & 0.19 & 1163 & 0.30 & 1195 & 0.94 & 1211 & 0.91 \\
\hline \multicolumn{16}{|c|}{ Parameters related to the metabolic syndrome } \\
\hline Parameters & BMI & 1165 & 0.68 & 1208 & 0.51 & 1207 & 0.88 & 1206 & 0.45 & 1163 & 0.26 & 1195 & 0.83 & 1211 & 0.86 \\
\hline \multirow{6}{*}{ related to obesity } & Weight & 1165 & 0.96 & 1208 & 0.59 & 1207 & 0.57 & 1206 & 0.53 & 1163 & 0.35 & 1195 & 0.39 & 1211 & 0.37 \\
\hline & Height & 1167 & 0.14 & 1211 & 0.075 & 1210 & 0.0024 & 1209 & 0.087 & 1166 & 0.0095 & 1198 & 0.098 & 1214 & 0.063 \\
\hline & Waist-to-hip ratio & 1167 & 0.087 & 1211 & 0.65 & 1210 & 0.37 & 1209 & 0.68 & 1166 & 0.63 & 1198 & 0.28 & 1214 & 0.34 \\
\hline & Hip circumference & 1166 & 0.75 & 1210 & 0.73 & 1209 & 0.67 & 1208 & 0.67 & 1165 & 0.065 & 1197 & 0.53 & 1213 & 0.52 \\
\hline & Body fat & 1157 & 0.49 & 1200 & 0.87 & 1199 & 0.63 & 1198 & 0.75 & 1156 & 0.064 & 1187 & 0.87 & 1203 & 0.80 \\
\hline & Adiponectin $^{\mathrm{a}}$ & 1154 & 0.14 & 1197 & 0.78 & 1196 & 0.14 & 1195 & 0.75 & 1153 & 0.10 & 1184 & 0.73 & 1200 & 0.84 \\
\hline Parameters & LDL cholesterol $^{\mathrm{a}}$ & 1162 & 0.96 & 1205 & 0.82 & 1204 & 0.25 & 1203 & 0.81 & 1160 & 0.77 & 1192 & 0.83 & 1208 & 0.69 \\
\hline & Total cholesterol ${ }^{\mathrm{a}}$ & 1164 & 0.92 & 1207 & 0.61 & 1206 & 0.63 & 1205 & 0.60 & 1162 & 0.84 & 1194 & 0.58 & 1210 & 0.56 \\
\hline \multirow{4}{*}{ hyperglycaemia } & $2 \mathrm{~h}$ glucose $^{\mathrm{a}}$ & 1165 & 0.014 & 1208 & 0.56 & 1207 & 0.46 & 1206 & 0.56 & 1163 & 0.68 & 1195 & 0.47 & 1211 & 0.47 \\
\hline & $\mathrm{HbA}_{1 \mathrm{c}}{ }^{\mathrm{a}}$ & 1164 & 0.38 & 1207 & 0.97 & 1206 & 0.71 & 1205 & 0.96 & 1162 & 0.88 & 1194 & 0.67 & 1210 & 0.82 \\
\hline & Insulin ${ }^{a}$ & 1161 & 0.93 & 1204 & 0.74 & 1203 & 0.26 & 1202 & 0.79 & 1159 & 0.82 & 1191 & 0.73 & 1207 & 0.81 \\
\hline & HOMA-IR* & 1164 & 0.99 & 1208 & 0.98 & 1207 & 0.44 & 1206 & 0.98 & 1163 & 0.78 & 1195 & 0.91 & 1211 & 0.88 \\
\hline & Leucocyte count ${ }^{\mathrm{a}}$ & 1165 & 0.71 & 1208 & 0.37 & 1207 & 0.97 & 1206 & 0.36 & 1163 & 0.047 & 1195 & 0.47 & 1211 & 0.53 \\
\hline \multirow{3}{*}{ parameters } & MCP- $1^{a}$ & 454 & 0.78 & 479 & 0.38 & 478 & 0.32 & 477 & 0.39 & 453 & 0.93 & 476 & 0.012 & 480 & 0.012 \\
\hline & IL- $6^{\star}$ & 1161 & 0.19 & 1205 & 0.044 & 1204 & 0.47 & 1203 & 0.080 & 1160 & 0.77 & 1192 & 0.82 & 1208 & 0.84 \\
\hline & Uric acid ${ }^{a}$ & 1165 & 0.027 & 1208 & 0.43 & 1207 & 0.086 & 1206 & 0.44 & 1163 & 0.34 & 1195 & 0.18 & 1211 & 0.29 \\
\hline
\end{tabular}

$P$, global $P$ value calculated in the model free model; $n$ analysed subjects; $c$, analysed controls; $m$, analysed subjects with metabolic syndrome; $d$, analysed type 2 diabetes mellitus cases; sys, systolic; dia, diastolic; all variables are adjusted for sex and age, ${ }^{\mathrm{B}} \mathrm{BMl} ;{ }^{*} P$ values from Kruskal-Wallis test; ${ }^{\dagger} P$ values from logistic regression; $P$ values below 0.05 are grey shaded. 
Table 3 Characteristics of non-diabetic survey participants aged 55-74 years.

\begin{tabular}{|c|c|c|c|}
\hline Parameters & $\boldsymbol{N}$ total $(\mathrm{m} / \mathrm{w})$ & Men & Women \\
\hline Age (years) & $1231(624 / 607)$ & $64.0 \pm 5.6$ & $63.8 \pm 5.4$ \\
\hline Body mass index $\left(\mathrm{kg} / \mathrm{m}^{2}\right)$ & $1227(621 / 606)$ & $28.0 \pm 3.5$ & $28.4 \pm 4.7$ \\
\hline Height $(\mathrm{cm})^{\mathrm{a}}$ & $1230(623 / 607)$ & $172 \pm 6.4$ & $159 \pm 6.1$ \\
\hline Weight $(\mathrm{kg})^{\mathrm{a}}$ & $1227(621 / 606)$ & $82.7 \pm 11.2$ & $71.9 \pm 12.0$ \\
\hline Body fat $(\%)^{a}$ & $1219(618 / 601)$ & $32.9 \pm 4.1$ & $40.3 \pm 5.0$ \\
\hline Waist-to-hip ratio ${ }^{a}$ & $1230(623 / 607)$ & $0.96 \pm 0.05$ & $0.84 \pm 0.06$ \\
\hline Waist circumference $(\mathrm{cm})^{\mathrm{a}}$ & $1230(558 / 586)$ & $99.9+9.3$ & $89.9+10.9$ \\
\hline Hip circumference $(\mathrm{cm})^{\mathrm{a}}$ & $1229(623 / 606)$ & $105 \pm 6.5$ & $107 \pm 9.4$ \\
\hline Uric acid $(\mathrm{mg} / \mathrm{dl})^{\mathrm{a}}$ & $1231(624 / 607)$ & $6.3 \pm 1.3$ & $4.9 \pm 1.1$ \\
\hline $\mathrm{HDL}$ cholesterol $(\mathrm{mmol} / \mathrm{l})^{\mathrm{a}}$ & $1229(622 / 606)$ & $1.4 \pm 0.4$ & $1.7 \pm 0.4$ \\
\hline LDL cholesterol (mmol/l) & $1228(622 / 584)$ & $3.9 \pm 1.0$ & $4.1 \pm 1.0$ \\
\hline Total cholesterol $\left(\mathrm{mmol} / \mathrm{l}^{\mathrm{a}}\right.$ & $1230(624 / 606)$ & $6.2 \pm 1.1$ & $6.5 \pm 1.1$ \\
\hline Fasting glucose $(\mathrm{mg} / \mathrm{dl})^{\mathrm{a}}$ & $1231(624 / 607)$ & $101 \pm 9.5$ & $96.9 \pm 9.2$ \\
\hline 2-h glucose $(\mathrm{mg} / \mathrm{dl})$ & $1231(624 / 607)$ & $115 \pm 33.1$ & $115 \pm 30.0$ \\
\hline Systolic blood pressure $(\mathrm{mmHg})^{\mathrm{a}}$ & $1227(621 / 606)$ & $139 \pm 18.8$ & $130 \pm 19.0$ \\
\hline Diastolic blood pressure $(\mathrm{mmHg})^{\mathrm{a}}$ & $1227(621 / 606)$ & $81.8 \pm 10.3$ & $77.7 \pm 9.8$ \\
\hline Leukocytes $\left(\times 10^{-3} / \mu \mathrm{l}\right)^{\mathrm{a}}$ & $1230(624 / 606)$ & $6.2 \pm 1.7$ & $5.9 \pm 1.3$ \\
\hline $\mathrm{HbA}_{1 \mathrm{c}}(\%)$ & $1229(623 / 606)$ & $5.55 \pm 0.35$ & $5.62 \pm 0.35$ \\
\hline HOMA-IR & $1224(621 / 603)$ & $2.5(1.6 / 3.7)$ & $2.3(1.6 / 3.4)$ \\
\hline Fasting insulin (mU/l) & $1224(621 / 603)$ & $9.9(6.9 / 12.3)$ & $9.6(6.9 / 13.8)$ \\
\hline Triglycerides $(\mathrm{mg} / \mathrm{dl})^{a}$ & $1219(617 / 602)$ & $120(82.0 / 165)$ & $104(81.0 / 143)$ \\
\hline Interleukin-6 (pg/ml) ${ }^{\mathrm{a}}$ & $1221(618 / 603)$ & $2.0(1.1 / 3.4)$ & $1.7(1.0 / 2.8)$ \\
\hline Adiponectin $(\mu \mathrm{g} / \mathrm{ml})^{\mathrm{a}}$ & $1217(618 / 599)$ & $7.5(5.3 / 9.9)$ & $11.5(8.7 / 15.0)$ \\
\hline $\mathrm{MCP}-1(\mathrm{pg} / \mathrm{ml})$ & $488(266 / 222)$ & $316(220 / 421)$ & $299(224 / 403)$ \\
\hline
\end{tabular}

Data are presented as means \pm s.D. or medians with 25 th and 75 th percentiles (in parentheses) for not normally distributed parameters. $\mathrm{m}$, men; $\mathrm{w}$, women. ${ }^{a} P<0.05$ for sex differences in age-adjusted linear regression analysis.

different between the genotype groups, although not significantly $(P=0.014)$. Most trends for differences between the genotype groups were observed within proinflammatory parameters. The highly correlated SNPs $c .{ }^{*} 65 C>T$ and $c^{*} 3879 C>T$ exhibited differences in MCP-1 levels (both $P=0.012$ ). Genotype groups of c.105T $>C$ and c. $-2138 A>T$ had different leucocyte counts and IL-6 levels respectively $(P=0.047,0.044)$. A difference in uric acid was observed between the genotype groups for $c .-3813 \mathrm{C}>T(P=0.027$; Table 2$)$.

\section{Discussion}

In the present study based on 1630 KORA S4 participants, we found that MCP-1 SNPs exhibit trends for association with triglyceride levels, fasting and 2-h glucose, height, leucocyte count, uric acid, MCP-1 and IL-6 levels. Significant associations were observed for only c.-928G>C in men and haplotype analysis with height.

\section{Metabolic syndrome and parameters from IDF definition}

Metabolic syndrome The concept of MetS as a distinct disorder is controversially discussed, but clarifying the pathway will contribute to discussion and may enhance the development of new medications $(12,36)$. Until now, studies assessing MetS and MCP-1 levels have been rare, yielded controversial results and have only been

Table 4 Analysed single nucleotide polymorphisms (SNPs) with allele and genotype frequencies, genotyping success rates, number of genotyped subjects and $P$ values of test for Hardy-Weinberg equilibrium (HWE).

\begin{tabular}{|c|c|c|c|c|c|c|c|c|}
\hline \multirow[b]{2}{*}{ SNP } & \multicolumn{2}{|c|}{ Allele frequency } & \multicolumn{3}{|c|}{ Genotype frequency } & \multirow[b]{2}{*}{$\begin{array}{c}\text { Call rate } \\
(\%)\end{array}$} & \multirow[b]{2}{*}{$n$} & \multirow[b]{2}{*}{$P$ HWE } \\
\hline & Major allele & Minor allele & $\begin{array}{l}\text { Homozygote } \\
\text { wild-type }\end{array}$ & Heterozygote & $\begin{array}{l}\text { Homozygote } \\
\text { minor }\end{array}$ & & & \\
\hline c. $-3813 C>T$ & C: 0.853 & T: 0.148 & CC: 0.725 & CT: 0.255 & TT: 0.020 & 95.8 & 1569 & 0.560 \\
\hline c. $-2138 A>T$ & A: 0.800 & T: 0.200 & AA: 0.641 & AT: 0.318 & TT: 0.041 & 98.9 & 1620 & 0.731 \\
\hline $\begin{array}{l}\text { c. }-928 G>C \\
\text { c. } 76+334 C>T\end{array}$ & G: 0.777 & C:0.223 & GG: 0.599 & $\begin{array}{c}\text { GC: } 0.356 \\
\text { Monomorphic }\end{array}$ & CC: 0.045 & 98.7 & 1617 & 0.360 \\
\hline c. $77-109 C>G$ & C:0.801 & G:0.199 & CC: 0.643 & GC: 0.316 & GG: 0.041 & 98.7 & 1616 & 0.740 \\
\hline $\begin{array}{l}\text { c. } 105 T>C \\
\text { c. } 194+25 C>T\end{array}$ & $\mathrm{~T}: 0.622$ & C:0.378 & TT: 0.390 & $\begin{array}{c}\text { TC: } 0.464 \\
\text { Monomorphic }\end{array}$ & CC: 0.146 & 95.2 & 1559 & 0.683 \\
\hline c. ${ }^{*} 65 C>T$ & C: 0.720 & $\mathrm{~T}: 0.281$ & CC: 0.516 & CT: 0.407 & TT: 0.077 & 97.9 & 1604 & 0.681 \\
\hline c. ${ }^{\star} 3879 C>T$ & C: 0.719 & $\mathrm{~T}: 0.282$ & CC: 0.515 & CT: 0.407 & TT: 0.078 & 98.9 & 1620 & 0.857 \\
\hline
\end{tabular}


Table 5 Haplotype analysis for height.

\begin{tabular}{|c|c|c|c|c|c|c|c|c|}
\hline Haplotype & Freq & c. $-3813 C>T$ & c. $-928 G>C$ & c. $77-109 C>G$ & $c .105 T>C$ & c. ${ }^{\star} 3879 C>T$ & B & $\boldsymbol{P}$ \\
\hline$M C P-1 * 1$ & 0.22 & C & C & C & $\mathbf{T}$ & C & 1.30 & 0.00020 \\
\hline$M C P-1 * 2$ & 0.09 & C & $\mathrm{G}$ & C & C & C & 0.19 & 0.71 \\
\hline$M C P-1 * 3$ & 0.21 & C & G & G & $\mathrm{T}$ & C & -0.099 & 0.78 \\
\hline$M C P-1 * 4$ & 0.15 & $\mathrm{~T}$ & $\mathrm{G}$ & C & T & C & 1.01 & 0.010 \\
\hline Rare & 0.05 & * & * & * & * & * & 0.23 & 0.72 \\
\hline Reference & 0.29 & C & $\mathrm{G}$ & C & C & T & & \\
\hline
\end{tabular}

$P$ values below 0.05 are grey shaded; $P$ values below 0.0004 are grey shaded and printed in bold; freq, frequency.

conducted on rather small populations $(<350$ individuals each) (37-39). The association between MCP-1 SNPs and MetS has not yet been investigated, but Kanda et al. recently suggested that MCP-1 may play an important role in the pathogenesis of MetS (9). In this study, neither an association nor a trend was observed for MetS. This suggests that MCP-1 SNPs indirectly influence MetS, as trends for associations with risk factors of MetS were found.

Triglyceride levels Epidemiological studies showed that higher MCP-1 levels were associated with higher triglycerides in healthy populations $(17,20,40,41)$. In small studies with $<160$ participants suffering from peripheral arterial disease and systemic lupus erythematosus, this association was also observed, although elevated MCP-1 levels may have been correlated with lipid abnormalities (42-44). Herder et al. found a significant positive association between systemic MCP1 and elevated triglyceride levels in 722 subjects of KORA S4, a subgroup of our study population (28). Our results indicate that MCP-1 may influence triglyceride levels. Other cytokines, like TNF $\alpha$ and IL-1, have been previously shown to be involved in the regulation of serum triglyceride levels $(45,46)$.

Fasting glucose Association analysis for MCP-1 SNPs with fasting glucose has also not been previously reported. Epidemiological studies revealed controversial results for a correlation of fasting glucose and MCP-1 levels in type 1 and 2 diabetic patients. This controversy might be due to the influence of blood glucose on MCP-1 production in several cell types and differential glycaemic control in diabetic patients $(47,48)$. In this study, a trend for differences in fasting glucose was found for the different genotypes of c.-928G>C. This finding is supported by the observation that MCP-1 interferes with insulin signalling, which leads to a reduction in glucose uptake by adipocytes (7).

Type 2 diabetes Several epidemiologic studies have been conducted to discover whether MCP-1 levels are associated with T2DM, although findings were inconsistent $(17,18,20-22)$. It was recently suggested that this inconsistency results from the confounding effect of cardiovascular and cerebrovascular conditions. Considering this fact, Herder et al. reported that MCP-1 levels were associated with risk for incident T2DM (17). Zietz et al. showed in a genetic study that 426 subjects with T2DM had significantly higher MCP-1 levels, but they were not associated with the SNP $-2578 A>G$. This lack of association might be due to co-medication with angiotensin converting enzyme inhibitors and lipid-lowering drugs, which can influence MCP-1 levels (18). In this work, no association was observed for any analysed SNP in the MCP-1 gene with T2DM, even when subjects taking lipid-lowering drugs were excluded from the analysis. This lack of association might be a power problem, as the analysed sample only included 254 T2DM cases. Larger association studies or a meta-analysis may be needed to exclude an influence of MCP-1 SNPs on T2DM.

\section{Parameters related to risk factors of metabolic syndrome}

Height Height was included in the analysis as a component of the BMI obesity parameter. Until now, no study has investigated an association of MCP-1 levels or MCP-1 SNPs with height. One recent study revealed an association of height with an IL-6 SNP. Grallert et al. suggested that IL-6 and other related cytokines exert an influence on osteoclast and osteoblast development and function (49). Rahimi et al. further reported that the MCP-1 protein is involved in osteoclast recruitment and development in mice (4). In this study, a trend was observed for c. $-928 G>C$ C c. $105 T>C$ and MCP- ${ }^{*} 4$ with height. Since height showed significant gender differences in the characteristics of the study population, it was further analysed separately for men and women. A significant association was observed in men, which implicated that the trend in the entire group was caused by men. Furthermore, haplotype analysis showed a statistically significant increase in height for carriers of $M C P-1 * 1$, which includes minor alleles of the two SNPs showing trends and $c^{*} 3879 C>T$ (Table 5). 
Accumulating evidence suggests that the receptor activator NF $\kappa$ B ligand (RANKL), among others, induces the MCP-1 protein production, leading to differentiation and higher activity of osteoclasts, which could lead to increased bone resorption (4, 50). Furthermore, Evans et al. showed that osteoclast activity exerts an influence on long bone length (51).

Two-hour glucose Epidemiological studies on MCP-1 and 2-h glucose are rare. Only two studies have been conducted and showed that there is no association of MCP-1 levels with 2-h glucose in a population-based approach or in patients with massive weight loss by bariatric surgery $(28,52)$. Similar to fasting glucose, no study has investigated the influence of MCP-1 SNPs on 2-h glucose. For c.-3813C $>$ T, a trend for higher 2-h glucose was observed between the genotype groups. This trend is also supported by the observation that MCP-1 reduces insulin-stimulated glucose uptake in adipocytes.

Leucocyte count Only $-2578 A>G$ was analysed for associations with leukocytes or subpopulations. In two studies of 550 and 150 participants respectively, no association of this SNP with higher leucocyte counts was observed $(53,54)$. In this analysis, the two SNPs in strong $\mathrm{LD}$ with $-2578 A>G$ showed no trend for differences in leukocytes between the genotype groups. However $c .105 T>C$ genotypes exhibited differences in leukocytes. This finding needs to be replicated, as there is no literature concerning an association of this SNP with serum leukocytes.

MCP-1 serum levels An association of SNP - 2578A> $G$ with MCP-1 serum levels was investigated by several studies $(18,20-23)$. Although functionality of this SNP has been previously demonstrated, the results of the association studies remain contradictory (24). The SNPs c. ${ }^{*} 65 \mathrm{C}>\mathrm{T}$ and $c .{ }^{*} 3879 \mathrm{C}>\mathrm{T}$ exhibited trends for different MCP-1 levels between the genotype groups. These SNPs were in strong $\mathrm{LD}$ with $-2578 A>G$, so our study did find previously demonstrated associations, even though MCP-1 levels were only measured in subjects with IGT and matched controls within each group comprising about 240 subjects. Glucose tolerance status did not correlate with MCP-1 levels (28).

IL-6 levels A single study investigated the association of the $M C P-1$ SNP $-2578 A>G$ with IL-6 levels. Zietz et al. detected a negative correlation $(P=0.025)$ (18). This was not observed for the two SNPs analysed, which were in strong LD with $-2578 A>G$. The SNP c. $-2138 A>T$ exhibited a trend for differences between the genotype groups, although the strongly correlated c. $77-109 C>G$ did not. Since MCP-1 is involved in IL-6 expression, an association seems conceivable (8), but further replication is necessary.

Uric acid Nakagawa et al. suggested uric acid to be related to MetS by inhibiting endothelial dysfunction (13). Therefore, uric acid was included in the present analysis. SNP c.-3813C $>T$ showed a trend for differences in serum uric acid between the genotype groups. There are no previous studies on MCP-1 or MCP-1 SNPs and uric acid. Thus, our finding must be replicated.

Strengths and limitations of the study The elderly KORA S4 study population is excellently suited for a candidate gene approach in the field of MetS genetics as it is suitably phenotyped for metabolic parameters, such as fasting triglycerides, fasting plasma glucose or HOMA-IR. To our knowledge, this survey, comprising 1630 subjects aged 55-74 years, is the largest population for MCP-1 SNPs providing an OGTT, which is of great relevance when investigating associations with T2DM, MetS or related parameters. In addition, we covered the whole $M C P-1$ gene, from $5 \mathrm{~kb}$ upstream to $5 \mathrm{~kb}$ downstream, in our analysis.

One limitation was that MCP-1 levels were only measured in about one third of the study participants, so the power for analysing this parameter was low. Furthermore, all results generated in subjects from 55 to 74 years cannot be transferred to other age groups.

\section{Conclusion}

In the present study, we analysed SNPs of the whole MCP-1 gene in a large population-based sample and revealed trends for differences between the genotype groups for several parameters of MetS. We provide the first suggestion of a potential association of MCP-1 SNPs with triglyceride levels and fasting glucose, two components of the IDF MetS definition. We propose to evaluate additional parameters for its relation to MCP-1: 2-h glucose, serum leukocytes, IL-6 levels and uric acid. Since c. $-3813 C>T$ exhibited trends for triglyceride levels, 2-h glucose and uric acid, it is a target SNP for further investigation. Another new finding was the significant association of $c .-928 \mathrm{G}>\mathrm{C}$ in men and $M C P-1 * 1$ with height. Although these new findings have to be replicated first, we conclude that MCP-1 may be an interesting gene for further investigation in MetS research.

\section{Acknowledgements}

The OGTT study was partly funded by the German Federal Ministry of Health, the Ministry of School, 
Science and Research of the State of North-RhineWestphalia, and the Anna Wunderlich-Ernst Jühling Foundation (WR, GG). Parts of this work were supported by the German Ministry of Education and Research (BMBF)/National Genome Research Network (NGFN) and the Deutsche Forschungsgemeinschaft (Wi621/12-1). The KORA Survey 4 was financed by the GSF, which is funded by the German Federal Ministry of Education, Science, Research and Technology and the State of Bavaria. The authors are indebted to K Papke (head of KORA Study Centre) and B Schwertner (survey organization) and their co-workers for organizing and conducting the data collection. We are grateful to the KORA Study Group (Head: Prof. H E Wichmann) for initiating the KORA Survey 4. We also thank all participants of the OGTT study. We further thank Christian Gieger and Guido Fischer for perfect data management.

\section{References}

1 Baggiolini M. Chemokines in pathology and medicine. Journal of Internal Medicine 2001250 91-104.

2 Gerhardt CC, Romero IA, Cancello R, Camoin L \& Strosberg AD. Chemokines control fat accumulation and leptin secretion by cultured human adipocytes. Molecular and Cellular Endocrinology 2001175 81-92.

3 Nelken NA, Coughlin SR, Gordon D \& Wilcox JN. Monocyte chemoattractant protein-1 in human atheromatous plaques. Journal of Clinical Investigation 199188 1121-1127.

4 Rahimi P, Wang CY, Stashenko P, Lee SK, Lorenzo JA \& Graves DT. Monocyte chemoattractant protein-1 expression and monocyte recruitment in osseous inflammation in the mouse. Endocrinology $19951362752-2759$.

5 Bruun JM, Lihn AS, Pedersen SB \& Richelsen B. Monocyte chemoattractant protein-1 release is higher in visceral than subcutaneous human adipose tissue (AT): implication of macrophages resident in the AT. Journal of Clinical Endocrinology and Metabolism 200590 2282-2289.

6 Ashida N, Arai H, Yamasaki M \& Kita T. Distinct signaling pathways for MCP-1-dependent integrin activation and chemotaxis. Journal of Biological Chemistry 2001276 16555-16560.

7 Sartipy P \& Loskutoff DJ. Monocyte chemoattractant protein 1 in obesity and insulin resistance. PNAS 2003100 7265-7270.

8 Viedt C, Vogel J, Athanasiou T, Shen W, Orth SR, Kubler W \& Kreuzer J. Monocyte chemoattractant protein-1 induces proliferation and interleukin- 6 production in human smooth muscle cells by differential activation of nuclear factor-kappaB and activator protein. Arteriosclerosis, Thrombosis, and Vascular Biology 200222 914-920.

9 Kanda H, Tateya S, Tamori Y, Kotani K, Hiasa K, Kitazawa R, Kitazawa S, Miyachi H, Maeda S, Egashira K \& Kasuga M. MCP-1 contributes to macrophage infiltration into adipose tissue, insulin resistance, and hepatic steatosis in obesity. Journal of Clinical Investigation 2006116 1494-1505.

10 Groop L \& Orho-Melander M. The dysmetabolic syndrome. Journal of Internal Medicine 2001250 105-120.

11 Lin HF, Boden-Albala B, Juo SH, Park N, Rundek T \& Sacco RL. Heritabilities of the metabolic syndrome and its components in the Northern Manhattan Family Study. Diabetologia 200548 2006-2012.

12 Eckel RH, Grundy SM \& Zimmet PZ. The metabolic syndrome. Lancet $20053651415-1428$.

13 Nakagawa T, Hu H, Zharikov S, Tuttle KR, Short RA, Glushakova O, Ouyang X, Feig DI, Block ER, Herrera-Acosta J,
Patel JM \& Johnson RJ. A causal role for uric acid in fructoseinduced metabolic syndrome. American Journal of Physiology. Renal Physiology 2006290 625-631.

14 Gerszten RE, Garcia-Zepeda EA, Lim YC, Yoshida M, Ding HA, Gimbrone MA Jr, Luster AD, Luscinskas FW \& Rosenzweig A. MCP-1 and IL-8 trigger firm adhesion of monocytes to vascular endothelium under flow conditions. Nature 1999398 718-723.

15 Randolph GJ \& Furie MB. A soluble gradient of endogenous monocyte chemoattractant protein-1 promotes the transendothelial migration of monocytes in vitro. Journal of Immunology 1995 $1553610-3618$.

16 Christiansen T, Richelsen B \& Bruun JM. Monocyte chemoattractant protein-1 is produced in isolated adipocytes, associated with adiposity and reduced after weight loss in morbid obese subjects. International Journal of Obesity 200529 146-150.

17 Herder C, Baumert J, Thorand B, Koenig W, de Jager W, Meisinger C, Illig T, Martin S \& Kolb H. Chemokines as risk factors for type 2 diabetes: results from the MONICA/KORA Augsburg study, 1984-2002. Diabetologia 200649 921-929.

18 Zietz B, Buchler C, Herfarth H, Muller-Ladner U, Spiegel D, Scholmerich J \& Schaffler A. Caucasian patients with type 2 diabetes mellitus have elevated levels of monocyte chemoattractant protein-1 that are not influenced by the $-2518 \mathrm{~A} \rightarrow \mathrm{G}$ promoter polymorphism. Diabetes, Obesity and Metabolism 20057 570-578.

19 Gosling J, Slaymaker S, Gu L, Tseng S, Zlot CH, Young SG, Rollins BJ \& Charo IF. MCP-1 deficiency reduces susceptibility to atherosclerosis in mice that overexpress human apolipoprotein B. Journal of Clinical Investigation 1999103 773-778.

20 McDermott DH, Yang Q, Kathiresan S, Cupples LA, Massaro JM, Keaney JF Jr, Larson MG, Vasan RS, Hirschhorn JN, O'Donnell CJ, Murphy PM \& Benjamin EJ. CCL2 polymorphisms are associated with serum monocyte chemoattractant protein-1 levels and myocardial infarction in the Framingham Heart Study. Circulation $20051121113-1120$.

21 Cermakova Z, Petrkova J, Arakelyan A, Drabek J, Mrazek F, Lukl J \& Petrek M. The MCP-1 -2518 (A to G) single nucleotide polymorphism is not associated with myocardial infarction in the Czech population. International Journal of Immunogenetics 2005 32 315-318.

22 Simeoni E, Hoffmann MM, Winkelmann BR, Ruiz J, Fleury S, Boehm BO, Marz W \& Vassalli G. Association between the A-2518G polymorphism in the monocyte chemoattractant protein-1 gene and insulin resistance and type 2 diabetes mellitus. Diabetologia 200447 1574-1580.

23 Tabara Y, Kohara K, Yamamoto Y, Igase M, Nakura J, Kondo I \& Miki T. Polymorphism of the monocyte chemoattractant protein (MCP-1) gene is associated with the plasma level of MCP-1 but not with carotid intima-media thickness. Hypertension Research 2003 26 677-683.

24 Rovin BH, Lu L \& Saxena R. A novel polymorphism in the MCP-1 gene regulatory region that influences MCP-1 expression. Biochemical and Biophysical Research Communications 1999259 344-348.

25 Holle R, Happich M, Lowel H \& Wichmann HE. KORA - a research platform for population based health research. Gesundheitswesen 200567 19-25.

26 Wichmann HE, Gieger C \& Illig T. KORA-gen-resource for population genetics, controls and a broad spectrum of disease phenotypes. Gesundheitswesen 200567 26-30.

27 Rathmann W, Haastert B, Icks A, Lowel H, Meisinger C, Holle R \& Giani G. High prevalence of undiagnosed diabetes mellitus in Southern Germany: target populations for efficient screening. The KORA survey 2000. Diabetologia 200346 182-189.

28 Herder C, Muller-Scholze S, Rating P, Koenig W, Thorand B, Haastert B, Holle R, Illig T, Rathmann W, Seissler J, Wichmann HE \& Kolb H. Systemic monocyte chemoattractant protein-1 concentrations are independent of type 2 diabetes or parameters of obesity: results from the Cooperative Health Research in the Region of Augsburg Survey S4 (KORA S4). European Journal of Endocrinology 2006154 311-317. 
29 Muller S, Martin S, Koenig W, Hanifi-Moghaddam P, Rathmann W, Haastert B, Giani G, Illig T, Thorand B \& Kolb H. Impaired glucose tolerance is associated with increased serum concentrations of interleukin 6 and co-regulated acute-phase proteins but not TNFalpha or its receptors. Diabetologia 200245 805-812.

30 Steffens M, Lamina C, Illig T, Bettecken T, Vogler R, Entz P, Suk EK, Toliat MR, Klopp N, Caliebe A, Konig IR, Kohler K, Ludemann J, Lacava AD, Fimmers R, Lichtner P, Ziegler A, Wolf A, Krawczak M, Nurnberg P, Hampe J, Schreiber S, Meitinger T, Wichmann HE, Roeder K, Wienker TF \& Baur MP. SNP-based analysis of genetic substructure in the German population. Human Heredity $2006 \mathbf{6 2}$ 20-29.

31 Winkelmann J, Lichtner P, Schormair B, Uhr M, Hauk S, StiasnyKolster K, Trenkwalder C, Paulus W, Peglau I, Eisensehr I, Illig T, Wichmann H-E, Pfister H, Golic H, Bettecken T, Pütz B, Holsboer F, Meitinger T \& Müller-Myhsok B. Variants in the XXX gene are associated with restless legs syndrome 2007 (unpublished observations).

32 Alberti KG, Zimmet P \& Shaw J. Metabolic syndrome - a new world-wide definition. A consensus statement from the International Diabetes Federation. Diabetic Medicine 200623 469-480.

33 Vollmert C, Windl O, Xiang W, Rosenberger A, Zerr I, Wichmann HE, Bickeboller H, Illig T \& Kretzschmar HA. Significant association of a M129V independent polymorphism in the $5^{\prime}$ UTR of the PRNP gene with sporadic Creutzfeldt-Jakob disease in a large German case-control study. Journal of Medical Genetics 200643 e53.

34 Nyholt DR. A simple correction for multiple testing for singlenucleotide polymorphisms in linkage disequilibrium with each other. American Journal of Human Genetics 2004 74 765-769.

35 Schaid DJ, Rowland CM, Tines DE, Jacobson RM \& Poland GA. Score tests for association between traits and haplotypes when linkage phase is ambiguous. American Journal of Human Genetics $200270425-434$.

36 Kahn R, Buse J, Ferrannini E \& Stern M. The metabolic syndrome: time for a critical appraisal: joint statement from the American Diabetes Association and the European Association for the Study of Diabetes. Diabetes Care 200528 2289-2304.

37 Lee WL, Lee WJ, Chen YT, Liu TJ, Liang KW, Ting CT \& HueyHerng SW. The presence of metabolic syndrome is independently associated with elevated serum CD40 ligand and disease severity in patients with symptomatic coronary artery disease. Metabolism 200655 1029-1034.

38 Liu MY, Xydakis AM, Hoogeveen RC, Jones PH, Smith EO, Nelson KW \& Ballantyne CM. Multiplexed analysis of biomarkers related to obesity and the metabolic syndrome in human plasma, using the Luminex-100 system. Clinical Chemistry 200551 1102-1109.

39 Marso SP, Murphy JW, House JA, Safley DM \& Harris WS Metabolic syndrome-mediated inflammation following elective percutaneous coronary intervention. Diabetes and Vascular Disease Research 20052 31-36.

40 Deo R, Khera A, McGuire DK, Murphy SA, Meo Neto JP, Morrow DA \& de Lemos JA. Association among plasma levels of monocyte chemoattractant protein-1, traditional cardiovascular risk factors, and subclinical atherosclerosis. Journal of the American College of Cardiology $2004 \mathbf{4 4} 1812-1818$.

41 Joven J, Coll B, Tous M, Ferre N, Alonso-Villaverde C, Parra S \& Camps J. The influence of HIV infection on the correlation between plasma concentrations of monocyte chemoattractant protein-1 and carotid atherosclerosis. Clinica Chimica Acta $2006 \mathbf{3 6 8}$ 114-119.
42 Asanuma Y, Chung CP, Oeser A, Shintani A, Stanley E, Raggi P \& Stein CM. Increased concentration of proatherogenic inflammatory cytokines in systemic lupus erythematosus: relationship to cardiovascular risk factors. Journal of Rheumatology 200633 $539-545$.

43 Kowalski J, Okopien B, Madej A, Makowiecka K, Zielinski M, Kalina Z \& Herman ZS. Levels of sICAM-1, sVCAM-1 and MCP-1 in patients with hyperlipoproteinemia IIa and -IIb. International Journal of Clinical Pharmacology and Therapeutics 200139 48-52.

44 Petrkova J, Szotkowska J, Hermanova Z, Lukl J \& Petrek M. Monocyte chemoattractant protein- 1 in patients with peripheral arterial disease. Mediators of Inflammation 200413 39-43.

45 Argiles JM, Lopez-Soriano FJ, Evans RD \& Williamson DH. Interleukin-1 and lipid metabolism in the rat. Biochemical Journal $1989259673-678$.

46 Grunfeld C, Adi S, Soued M, Moser A, Fiers W \& Feingold KR. Search for mediators of the lipogenic effects of tumor necrosis factor: potential role for interleukin 6. Cancer Research $1990 \mathbf{5 0}$ 4233-4238.

47 Mine S, Okada Y, Tanikawa T, Kawahara C, Tabata T \& Tanaka Y. Increased expression levels of monocyte CCR2 and monocyte chemoattractant protein-1 in patients with diabetes mellitus. Biochemical and Biophysical Research Communications 2006344 780-785.

48 Takebayashi K, Matsumoto S, Aso Y \& Inukai T. Association between circulating monocyte chemoattractant protein-1 and urinary albumin excretion in nonobese type 2 diabetic patients. Journal of Diabetes and its Complications 200620 98-104.

49 Grallert H, Huth C, Kolz M, Meisinger C, Herder C, Strassburger K, Giani G, Wichmann HE, Adamski J, Illig T \& Rathmann W. IL-6 promoter polymorphisms and quantitative traits related to the metabolic syndrome in KORA S4. Experimental Gerontology 2006 41 737-745.

50 Kim MS, Day CJ \& Morrison NA. MCP-1 is induced by receptor activator of nuclear factor-\{kappa\}B ligand, promotes human osteoclast fusion, and rescues granulocyte macrophage colonystimulating factor suppression of osteoclast formation. Journal of Biological Chemistry $200528016163-16169$.

51 Evans KD, Lau ST, Oberbauer AM \& Martin RB. Alendronate affects long bone length and growth plate morphology in the oim mouse model for Osteogenesis Imperfecta. Bone 200332 268-274.

52 Schernthaner GH, Kopp HP, Kriwanek S, Krzyzanowska K, Satler M, Koppensteiner R \& Schernthaner G. Effect of massive weight loss induced by bariatric surgery on serum levels of interleukin-18 and monocyte-chemoattractant-protein-1 in morbid obesity. Obesity Surgery $200616709-715$.

53 Franco-Lopez E, Gonzalez-Escribano MF, Aguilera I, Pascasio JM, Pareja F, Bernardos A \& Nunez-Roldan A. Lack of association of recipient MCP-1 gene promoter polymorphism with acute graft rejection after orthotopic liver transplantation. Transplantation Proceedings 200537 1496-1498.

54 Kozma GT, Falus A, Bojszko A, Krikovszky D, Szabo T, Nagy A \& Szalai C. Lack of association between atopic eczema/dermatitis syndrome and polymorphisms in the promoter region of RANTES and regulatory region of MCP-1. Allergy 200257 160-163.

Received 29 September 2006

Accepted 14 December 2006 